\title{
Wer hat den Sinn so verdreht?
}

\author{
Über den korrekten Umgang mit \\ dem Aut-idem-Kreuz informierten \\ wir in MMW 13/2012, S. 8. Ein Le- \\ ser hält den Vorgang - zumindest \\ sprachlich - für reichlich unsinnig:
}

- Aut idem kommt aus dem Lateinischen und heißt so viel wie „oder ein anderes (Medikament)“. Wird es beim Ausstellen eines Rezeptes vom Doktor angekreuzt, dann sollte man annehmen, der Arzt gibt dem Apotheker die Anweisung, gegebenenfalls statt des rezeptierten Medikamentes auch ein anderes mit der gleichen Wirkstoffgruppe abzugeben.

Ein der lateinische Sprache mächtiger Patient wird dann allerdings feststellen, dass es gerade umgekehrt ist. Gibt der Doktor also durch Ankreuzen des „Aut idem“-Kästchens die ausdrückliche Anweisung, auch ein anderes Me- dikament abgeben zu dürfen, wird der Apotheker von den Kassen dazu angehalten, nur das auf dem Rezept aufgeführte Medikament abzugeben. Es ist einfach unglaublich: Ein paar der lateinischen Sprache nicht mächtige Leithammel verdrehen einen Sachverhalt ins Gegenteil und die akademische Schafsherde folgt ihnen ohne zu zögern.

- Dr. med. Udo Fuchs, Hamburg

\section{Wann ist die Chance auf Mutterschaft vertan?}

\section{Beratungsbedarf zur künstlichen Befruchtung ist um mehrere $100 \%$ gestiegen}

\begin{abstract}
Paare entscheiden sich heute immer später zum Kind. Welche Risiken die späte Vaterschaft birgt und wie die Chancen auf spätes Mutterglück medizinisch erhöht werden können, war Thema unseres Schwerpunkts in MMW Nr. 13/2012, S. 42 ff. Dazu ein Leser:
\end{abstract}

— Den Eindruck, den die Autoren äuBerten, nämlich, dass viele Paare die Familienplanung immer weiter hinausschieben, kann ich nur bestätigen. Versicherungsmedizinische Anfragen etwa zur medizinischen Notwendigkeit von intrauteriner Insemination, In-vitroFertilisation (IVF) und intrazytoplasmatischer Spermieninjektion (ICSI) haben seit den 1990-iger Jahren um mehrere $100 \%$ zugenommen.

Bei den meisten Fällen, die mir vorliegen, ist die Frau zwischen 38 und 42 Jahren alt. Dass die natürliche Fertilität im 39. Lebensjahr bereits drastisch gesunken und im 42. Lebensjahr kaum noch vorhanden ist, ist reproduktionsmedizinische Propädeutik. Oft hat die Frau bis zum 35. Lebensjahr oder länger

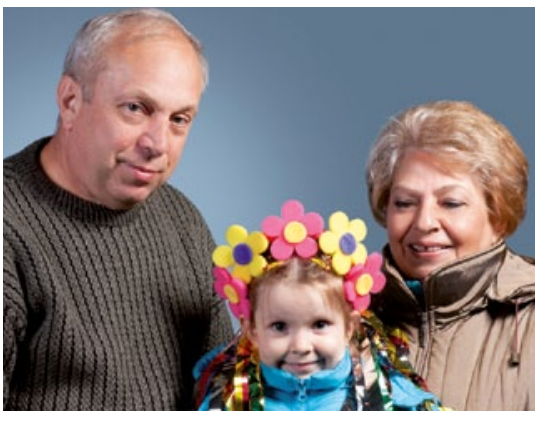

Familienidyll mit den Großeltern - oder mit den Eltern?

hormonell verhütet. Dann kommt es beim Absetzen der Ovulationshemmer natürlich auch nicht gleich zur Konzeption.

Sind Mann und Frau bei verschiedenen Krankenkassen versichert, wird es noch komplizierter. Es stellt sich dann auch noch die Verursacherfrage. 40-jährige Frauen haben zwar in der Regel physiologischerweise kaum mehr eine natürliche Fertilität, die Untersuchungen auf eine organische Fertilitätsstörung sind aber trotzdem häufig unauffällig. Liegen im Spermiogramm des Mannes dann grenzwertige oder sub- normale Teilqualitäten vor, so wird die organische Verursachung von Kinderwunschzentren dann oft dem Mann zugeschrieben und das Alter der Frau bei der Verursacherfrage vernachlässigt. Dies ist von Bedeutung, weil die Versicherungsbedingungen bei künstlicher Befruchtung auf organische Störungen abheben.

Paare verlassen sich offenbar heute darauf, dass mit den Mitteln von IVF und ICSI auch bei hohem weiblichen Alter noch Vieles erreichbar ist. Oft stimmt das, allerdings kommt es mit zunehmendem Alter der Frau auch zu einem erhöhten Abortrisiko sowie zu Gesundheitsrisiken für das neugeborene Kind wie z. B. Typ-1-Diabetes und chronisch entzündliche Darmerkrankungen. Darüber hinaus belasten die Kosten für die künstliche Befruchtung (im fünfstelligen Bereich) die Versicherungsgemeinschaft erheblich.

- Dr. med. Rainer Hakimi, leitender Gesellschaftsarzt, Hallesche Krankenversicherung a. G., Reinsburgstraße 10, D-70178 Stuttgart 